\title{
"Silent" Metaplasticity of the Late Phase of Long-Term Potentiation Requires Protein Phosphatases
}

\author{
Newton H. Woo ${ }^{1}$ and Peter V. Nguyen ${ }^{1,2,3,4}$ \\ Departments of Physiology ${ }^{1}$ and Psychiatry, ${ }^{2}$ Centre for Neuroscience, ${ }^{3}$ University of Alberta School of Medicine, \\ Edmonton, Alberta, T6G 2H7, Canada
}

\begin{abstract}
The late phase of long-term potentiation (L-LTP) is correlated with some types of long-term memory, but the mechanisms by which L-LTP is modulated by prior synaptic activity are undefined. Activation of protein phosphatases by low-frequency stimulation (LFS) given before induction of L-LTP may significantly modify L-LTP. Using cellular electrophysiological recording methods in mouse hippocampal slices, we show that LFS given before induction of L-LTP inhibited L-LTP in an activity-dependent manner without affecting either basal synaptic strength or the early phase of LTP (E-LTP). This anterograde inhibitory effect of LFS was persistent, required N-methyl-D-aspartate (NMDA) receptor activation, and was blocked by inhibitors of protein phosphatase 1 (PP1) and protein phosphatase 2A (PP2A). These data indicate that certain patterns of LFS can activate PP1 and/or PP2A, and that long-lasting activation of these phosphatases by prior LFS can suppress the subsequent expression of L-LTP without affecting E-LTP. Because this inhibition of L-LTP is caused by prior synaptic activity that, alone, produced no net effect on synaptic efficacy, we suggest that this is a "silent" form of metaplasticity that may influence long-term information storage by modulating the capacity of synapses to express L-LTP after repeated bouts of activity.
\end{abstract}

Long-term potentiation (LTP) is an enhancement of synaptic strength (Bliss and Lomo 1973; Schwartzkroin and Wester 1975; Alger and Teyler 1976; Andersen et al. 1977) believed to be an important regulator of some types of learning and memory (Bliss and Collingridge 1993; Moser et al. 1998; Martin et al. 2000; Brun et al. 2001). LTP has at least two temporal phases: an early phase (E-LTP) and a late phase (L-LTP) (Krug et al. 1984; Huang and Kandel 1994; Huang et al. 1996; see also Winder et al. 1998 for an "intermediate" phase of LTP). In area CA1 of hippocampal slices, E-LTP is induced by a single train of $100-\mathrm{Hz}$ stimulation and can last for 1-2 hr (Huang and Kandel 1994; for reviews, see Bliss and Collingridge 1993 and Huang et al. 1996). In contrast, L-LTP is induced by multiple trains of $100-\mathrm{Hz}$ stimulation and may last for several hours (Andersen et al. 1977; Huang and Kandel 1994; Abel et al. 1997). Unlike E-LTP, expression of L-LTP requires activation of cAMP-dependent protein kinase (PKA) (Frey et al. 1993; Matthies and Reymann 1993; Abel et al. 1997), transcription (Nguyen et al. 1994), and protein synthesis (Stanton and Sarvey 1984; Frey et al. 1988). Although the biochemical signaling mechanisms underlying L-LTP are well characterized (for reviews, see Huang et al. 1996 and Kandel 2001), nothing is known

${ }^{4}$ Corresponding author.

E-MAIL Peter.Nguyen@ualberta.ca; FAX 780-492-8915.

Article and publication are at http://www.learnmem.org/cgi/doi/ $10.1101 / \mathrm{lm} .498402$. about the mechanisms that underlie the modulation of LLTP expression by prior synaptic activity.

"Metaplasticity" is the modulation of synaptic plasticity by previously imposed activity (Yang and Faber 1991; Huang et al. 1992; Dudek and Bear 1993; Wexler and Stanton 1993; for reviews, see Abraham and Bear 1996 and Abraham and Tate 1997). An example of metaplasticity is "priming" of synapses using high-frequency stimulation (HFS), which can facilitate subsequent induction of longterm depression (LTD) (Dudek and Bear 1992) (Christie and Abraham 1992; Wexler and Stanton 1993). Conversely, lowfrequency stimulation (LFS) that is subthreshold for inducing synaptic plasticity ("innocuous" LFS) can impair subsequent LTP induction (Christie and Abraham 1992; Huang et al. 1992; Fujii et al. 1996) or it can erase previously established LTP ("depotentiation" or DPT; Barrionuevo et al. 1980; Staubli and Lynch 1990; Fujii et al. 1991). LFS-induced LTD and DPT both require phosphatases for their induction (Mulkey et al. 1993, 1994; O'Dell and Kandel 1994), but the roles of phosphatases in metaplasticity of LTP, elicited by prior innocuous patterns of LFS, are undefined.

Studies of hippocampal metaplasticity have examined the roles of activity in regulating the subsequent induction and expression of LTP without making a clear distinction between the E-LTP and L-LTP. Differential, anterograde regulation of expression of E-LTP or L-LTP by prior synaptic activity and the possible involvement of phosphatases in such regulation have not been explored. Mammalian neu-

LEARNING \& MEMORY 9:202-213 @ 2002 by Cold Spring Harbor Laboratory Press ISSN1072-0502/02 \$5.00

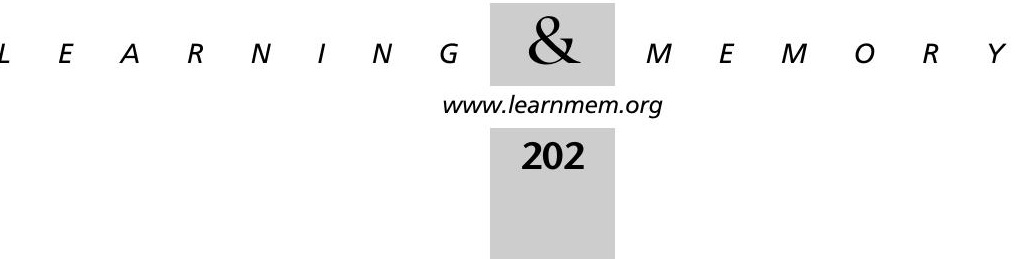


rons receive thousands of synaptic inputs, many of which may be subthreshold for altering synaptic strength. These inputs may, nonetheless, alter the capability of neurons to undergo lasting changes in synaptic strength, such as L-LTP, in response to future activity. Because L-LTP is linked to some forms of long-term memory in mice (Abel et al. 1997), identifying the mechanisms by which innocuous synaptic activity elicits anterograde regulation of L-LTP may shed light on the question of how long-term memory is influenced by previous neural experience.

In this study, we asked the following central question: Can innocuous synaptic activity, imposed before HFS, critically modulate the subsequent expression of L-LTP? We show that LFS before HFS does not modify E-LTP, but it does selectively inhibit the expression of L-LTP. When applied by itself, LFS had no lasting effects on synaptic strength. This anterograde inhibition of L-LTP is persistent, and it is dependent on the amount and frequency of prior LFS. Anterograde inhibition of L-LTP by LFS was blocked by inhibitors of protein phosphatase 1 (PP1) and protein phosphatase 2A (PP2A), and it required activation of N-methyl-D-aspartate (NMDA) receptors during LFS. Because this inhibition of L-LTP is caused by prior synaptic activity that alone produced no net effect on synaptic efficacy, we suggest that this is a "silent" form of metaplasticity that may influence long-term information storage by modulating the capacity of synapses to express L-LTP after repeated bouts of activity.

\section{RESULTS}

\section{LFS Reverses E-LTP When Given} After, but Not Before, Its Induction LFS elicits LTD in hippocampal slices (Dudek and Bear 1992; Abraham and Bear 1996; Montgomery and Madison 2002), and expression of LTD is age-dependent: Hippocampal slices from very young animals show robust LTD, whereas slices from adult animals lack, or show attenuated, LTD after LFS (Dudek and Bear 1992; Mulkey and Malenka 1992; Mayford et al. 1995; Wagner and Alger 1995). LFS can also induce DPT, which is a rapid reversal of LTP previously elicited by HFS (Barrionuevo et al. 1980; Staubli and Lynch 1990; Fujii et al. 1991). As an initial step toward characterizing the effects of innocuous LFS on subsequent expression of L-LTP, we wanted to use an LFS protocol that would not induce persistent or significant changes in field excitatory postsynaptic potential (fEPSP) slopes. A previous study has shown that 5-Hz LFS for 3 min does not persistently alter fEPSPs in area CA1 of mouse slices (Thomas et al. 1996). We thereby examined synaptic efficacy after LFS in area CA1 of hippocampal slices cut from mice that were 9-12 wk of age. We found that LFS at $5 \mathrm{~Hz}$ for 3 min elicited only a transient synaptic depression (Fig. 1A), consistent with the findings of Thomas et al. (1996). Mean fEPSP slopes were initially depressed to $67 \pm 5 \%$ of pre-LFS values, but they recovered to pre-LFS fEPSP slope values within $7 \mathrm{~min}$ after LFS (Fig. 1A). We refer to this protocol as "innocuous LFS," because it elicited no persistent changes in synaptic efficacy under these conditions (Thomas et al. 1996, 1998; see also Winder et al. 1999). However, this innocuous LFS protocol induced rapid DPT when given 5 min after two trains of $100 \mathrm{~Hz}$ (20 sec apart) (Fig. 1B,C), thereby confirming the results of other studies performed on rat and guinea pig slices (Barrionuevo et al. 1980; Staubli and Lynch 1990; Fujii et al. 1991, O’Dell and Kandel 1994). This rapid, retrograde influence of LFS on previously induced LTP represents a form of metaplasticity in which erasure of LTP is caused by LFS applied after LTP induction.
A

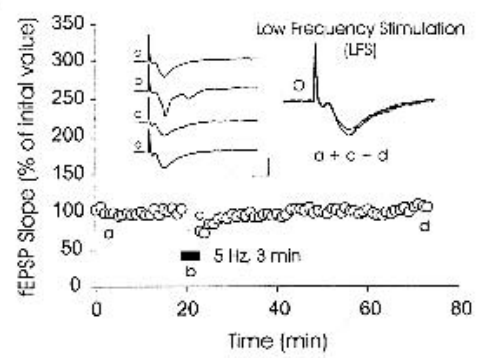

C

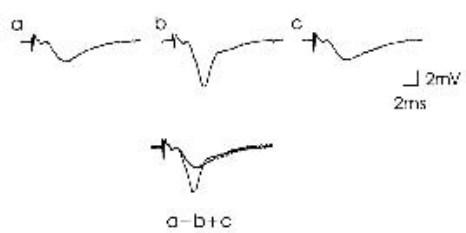

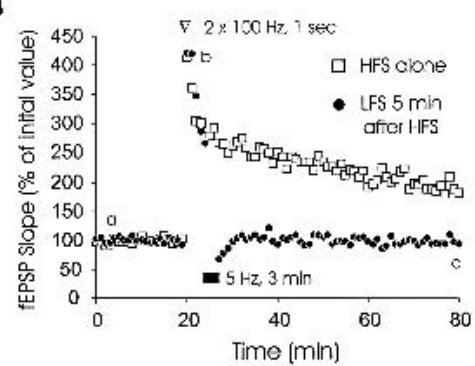

D

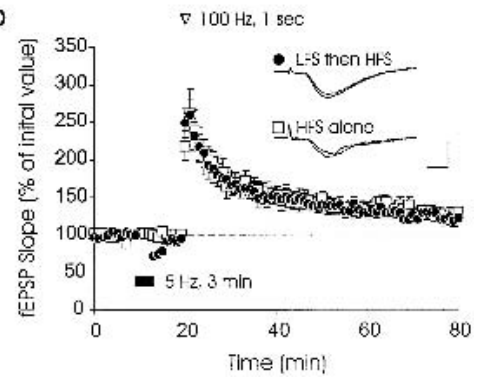

Figure 1 Low-frequency stimulation (LFS) does not affect either basal synaptic transmission or the early phase of long-term potentiation (E-LTP). (A) Transient depression was observed after $5-\mathrm{Hz}$ stimulation (for $3 \mathrm{~min}$ ) was applied to area CA1 of hippocampal slices. However, field excitatory postsynaptic potential (fEPSP) slopes recovered back to pre-LFS slope values within $7 \mathrm{~min}$ after the end of LFS $(\bigcirc \mathrm{n}=9)$. Sample fEPSP traces from one experiment are shown; these were recorded $15 \mathrm{~min}$ before $(a)$, during $(b)$, immediately after $(c)$, and 20 min after $(d)$, LFS. Calibration bars: $2 \mathrm{mV}, 4 \mathrm{~ms}$. $(B)$ LFS at $5 \mathrm{~Hz}$, applied after two trains of $100 \mathrm{~Hz}$, (1-sec duration, spaced $20 \mathrm{sec}$ apart), erases previously established LTP (depotentiation [DPT]). (C) Sample fEPSP traces recorded from one experiment at time points labeled in part B. $(D)$ Prior LFS at $5 \mathrm{~Hz}$ does not affect E-LTP induced by a single $100-\mathrm{Hz}$ train. Control slices $(\square \mathrm{n}=6)$ generated E-LTP that was similar in magnitude and time course to E-LTP induced in slices that received LFS before tetanization $(n=6)$. Inset: Sample fEPSP traces from one experiment, measured $10 \mathrm{~min}$ before and $60 \mathrm{~min}$ after E-LTP induction. Calibration bars: $2 \mathrm{mV}, 2 \mathrm{~ms}$.

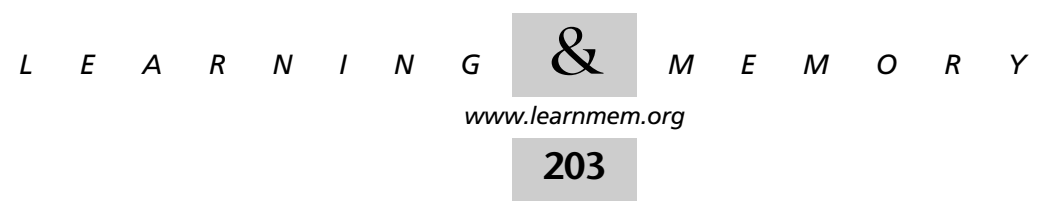


Can the same LFS protocol affect LTP induction or expression when applied before its induction?

To address this question, we imposed a 7-min interval between the end of LFS and the start of HFS for LTP induction. This time period was sufficient to allow fEPSPs to fully recover to pre-LFS fEPSP slope values after LFS (Fig. 1A). We first tested an HFS protocol that elicits E-LTP, consisting of a single train of $100 \mathrm{~Hz}$ (1-sec duration) (Huang and Kandel 1994). We found that E-LTP gradually decayed to $130 \pm 7 \%$ at $1 \mathrm{hr}$ after induction (Fig. 1D, $\square$ ). Slices receiving innocuous LFS before induction of E-LTP (Fig. 1D, O) showed potentiation that was similar in time course and magnitude to E-LTP seen in slices receiving only HFS: The mean fEPSP slope measured in slices receiving LFS before HFS was $123 \pm 5 \%$ of pre-LFS values ( $1 \mathrm{hr}$ after E-LTP induction; Fig. $1 \mathrm{D}, p>.1$ for comparison with experiments using HFS alone, at all time points tested). Thus, innocuous LFS at $5 \mathrm{~Hz}$ had no significant effect on the induction or expression of E-LTP when it was applied before E-LTP induction. These data underscore the idea that the time of application of LFS is critical in determining whether LTP can be modulated by LFS (Abraham and Bear 1996).

\section{Anterograde Modulation of L-LTP by Prior Innocuous LFS}

Does innocuous LFS affect subsequent induction or expression of L-LTP? To address this question, we used a tetraburst protocol that elicits L-LTP in mouse hippocampal slices (Abel et al. 1997; Nguyen et al. 2000; Woo et al. 2000); this consisted of four trains of $100 \mathrm{~Hz}$, each 1-sec duration and spaced 5 min apart (Fig. 2A). This regimen produced robust L-LTP in area CA1 of hippocampal slices: fEPSP slopes remained potentiated for at least $2 \mathrm{hr}$ (Fig. 2B, $\square$ ). However, slices receiving innocuous LFS at $5 \mathrm{~Hz}$ (for $3 \mathrm{~min}$, equivalent to 900 pulses) before tetraburst stimulation showed a significant reduction in the magnitude of L-LTP beginning at 20 min postinduction. L-LTP decayed back to near pre-LFS fEPSP slope values within $100 \mathrm{~min}$ (Fig. 2B, O). Mean fEPSP slopes measured $5 \mathrm{~min}$ and $2 \mathrm{hr}$ after L-LTP induction in control slices receiving no LFS were $332 \pm 45 \%$ and

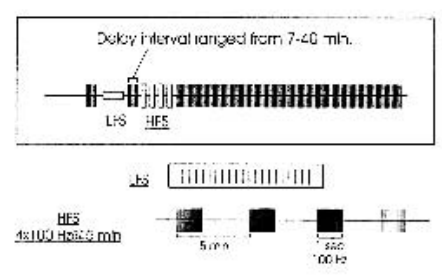

B

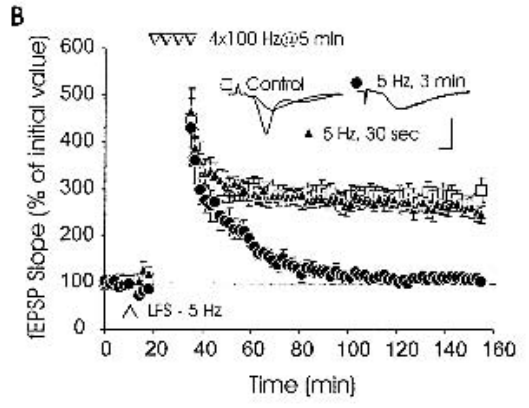

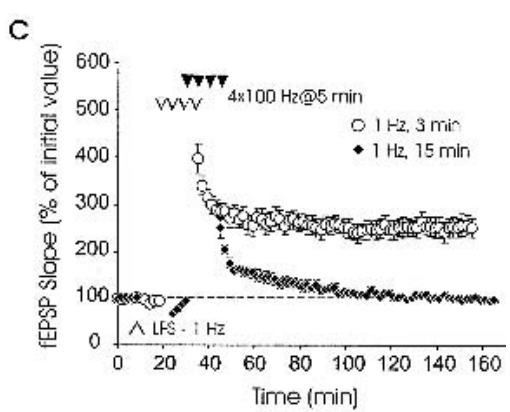

E

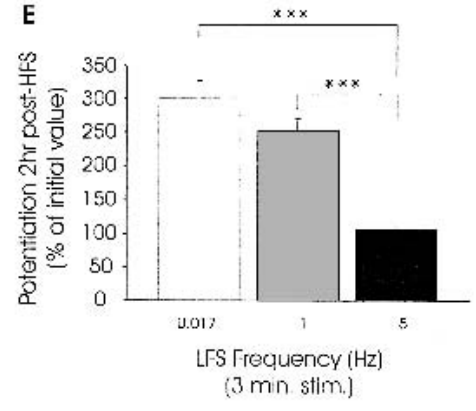

Figure 2 Activity-dependent anterograde metaplasticity of the late phase of LTP (L-LTP). (A) Experimental protocols used for synaptic stimulation of hippocampal slices. LFS was applied by giving $5-\mathrm{Hz}$ or $1-\mathrm{Hz}$ stimulation for various durations (see Materials and Methods). Subsequent LTP was then induced by applying four $100-\mathrm{Hz}$ trains spaced 5 min apart (tetraburst stimulation). fEPSPs were monitored for 2 hr postinduction. The interval between LFS and subsequent induction of LTP ranged from $7-40$ min. $(B)$ Tetraburst stimulation reveals a deficit in L-LTP when LFS (5 Hz, 3 min) was given before induction of L-LTP. Four successive trains of 100-Hz, spaced 5 min apart, induced robust L-LTP in control slices $(\square, n=5)$ and in slices that received a brief prior episode of LFS (5 Hz, 30 sec; triangles, $n=5$ ). No L-LTP was seen in slices that received more prolonged LFS $(5 \mathrm{~Hz}, 3 \mathrm{~min}$; circles, $\mathrm{n}=5)$ before high-frequency stimulation (HFS). Inset: Sample traces from an experiment, measured $10 \mathrm{~min}$ before and $2 \mathrm{hr}$ after L-LTP induction. Calibration bars: $5 \mathrm{mV}, 2 \mathrm{~ms}$. (C) Anterograde metaplastic inhibition of L-LTP expression is frequency-dependent. Decreasing the frequency of LFS to $1 \mathrm{~Hz}$, without altering the duration of stimulation (1 Hz, 3 $\min ; \mathrm{O}, \mathrm{n}=6$ ), had no effect on subsequent L-LTP. However, when 1-Hz LFS was increased to 15 min in duration, L-LTP was blocked and E-LTP was attenuated $(1 \mathrm{~Hz}, 15 \mathrm{~min} ;, \mathrm{n}=5)$. (D) Summary histogram showing mean levels of potentiation seen when the number of pulses during prior LFS was varied at a constant frequency of $5 \mathrm{~Hz}(* * *$ denotes $p<.001)$. (E) Summary histogram depicting the level of potentiation observed when only the frequency of prior LFS was varied (duration of stimulation was constant at 3 min).

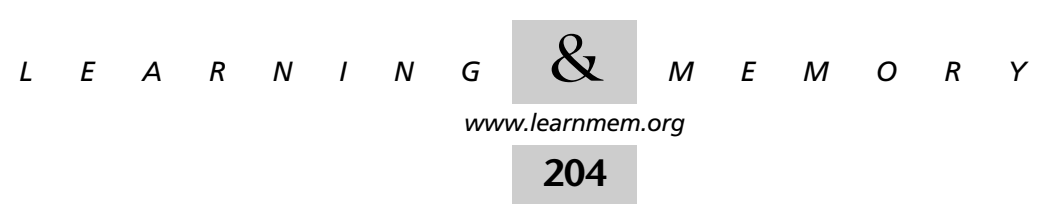


$300 \pm 27 \%$, respectively (Fig. 2B). In slices receiving innocuous LFS before induction of L-LTP, the corresponding slope values were $283 \pm 32 \%$ and $105 \pm 6 \%$, respectively (Fig. 2B, $0 ; p<.01$ for $2 \mathrm{hr}$ value).

We next explored the effects of varying the duration of LFS on subsequent L-LTP. When the duration of LFS was decreased to $30 \mathrm{sec}$ (keeping the frequency constant at 5 $\mathrm{Hz}$ ), L-LTP elicited by subsequent HFS was intact (Fig. 2B, triangles). Mean fEPSP slopes, measured $5 \mathrm{~min}$ and $2 \mathrm{hr}$ post-HFS, were $337 \pm 32 \%$ and $248 \pm 20 \%$, respectively, in slices receiving prior LFS at $5 \mathrm{~Hz}, 30 \mathrm{sec}(p>.1$, for comparison with control slices at all time points tested). Thus, a critical number of pulses during LFS is required for LFSinduced suppression of L-LTP.

We next investigated the effects of giving 900 pulses at a lower frequency, $1 \mathrm{~Hz}$ (i.e., $1 \mathrm{~Hz}$ for $15 \mathrm{~min}$ ). Like $5-\mathrm{Hz}$ LFS, this 1-Hz protocol blocked expression of L-LTP. However, it also significantly attenuated initial potentiation (Fig. $2 \mathrm{C}$, ). The initial potentiation seen after HFS with prior 1-Hz LFS was significantly smaller than the potentiation seen after HFS alone (compare squares of Fig. 2B with diamonds of Fig. $2 \mathrm{C}, p<.05)$. Because the early phase was attenuated with 900 pulses at $1 \mathrm{~Hz}$ (Fig. 2C), we tested the effects of reducing the total number of pulses applied at $1 \mathrm{~Hz}$. We found that a $1-\mathrm{Hz}, 3-\mathrm{min}$ regimen produced a smaller initial depression of fEPSPs (mean fEPSP slopes were $89 \pm 5 \%$ of pre-LFS values) than $5-\mathrm{Hz}$ stimulation $(74 \pm 5 \%$ of pre-LFS values), but this depression recovered fully to pre-LFS fEPSP slope values before HFS (Fig. 2C, O). When HFS was applied 7 min after 1-Hz, 3 min LFS, we observed L-LTP similar to that seen in control slices receiving only HFS (compare Fig. 2C $\bigcirc$ and Fig. 2B $\square$ ). Mean values for fEPSP slopes measured $5 \mathrm{~min}$ and $2 \mathrm{hr}$ post-HFS in slices receiving $1-\mathrm{Hz}$ 3 -min stimulation were $315 \pm 17 \%$ and $251 \pm 19 \%$, respectively. These values were not significantly different from corresponding values measured from slices receiving only HFS $(p>.2)$. Our data are summarized in the histograms of Figure $2 \mathrm{D}$ and $\mathrm{E}$.

These findings establish, for the first time in the literature, that innocuous LFS at $5 \mathrm{~Hz}$ for 3 min selectively inhibits expression of multi-train L-LTP, without affecting singletrain E-LTP, when given before L-LTP induction. This anterograde metaplasticity of L-LTP is dependent on both the amount and the frequency of LFS applied before L-LTP induction.

\section{LFS Cannot Reverse L-LTP}

Because innocuous LFS before tetraburst stimulation inhibits the expression of L-LTP, we asked whether LFS applied shortly after L-LTP induction could reverse, or depotentiate, L-LTP. To date, DPT of tetraburst L-LTP by $5-\mathrm{Hz}$ stimulation has not been examined. We found that LFS $(5 \mathrm{~Hz}, 3 \mathrm{~min}) \mathrm{did}$ not depotentiate L-LTP (Fig. 3A, triangles). Thus, innocuous
LFS at $5 \mathrm{~Hz}, 3 \mathrm{~min}$ cannot reverse L-LTP in a retrograde manner.

\section{The Inhibitory Effect of Innocuous LFS Is Limited in Its Duration of Action}

Previous studies have shown that there is a narrow critical time window within which LFS effectively erases previously induced LTP (O'Dell and Kandel 1994; for mossy fiber data, see also Chen et al. 2001). LFS effectively erases LTP when given within the first 5-10 min after LTP induction (O'Dell and Kandel 1994). In contrast, LFS is less effective at persistently reversing LTP when applied $20 \mathrm{~min}$ after LTP induction (O'Dell and Kandel 1994). It is unclear whether a time window of effectiveness also exists for the inhibitory influence of LFS applied before L-LTP. Can innocuous LFS exert anterograde inhibition of L-LTP over an extended period of time before L-LTP induction?

We tested the effect of innocuous LFS on L-LTP with a 20-min or 40-min delay period imposed between the end of LFS and the start of HFS (Fig. 3B,C). We found that a 20-min delay still permitted innocuous LFS $(5 \mathrm{~Hz}, 3 \mathrm{~min})$ to significantly attenuate L-LTP (Fig. 3B, O). Mean fEPSP slopes measured $5 \mathrm{~min}$ and $2 \mathrm{hr}$ after L-LTP induction in LFS slices were $278 \pm 25 \%$ and $106 \pm 8 \%$, respectively. The mean fEPSP slope value measured 2 hr post-HFS using the 20-min LFSHFS delay period was significantly lower than the corresponding value measured from slices receiving only HFS $(p>.1$, at all time points), but it was not significantly different from the mean slope value measured from slices receiving LFS with a 7-min delay period (Fig. 3C). However, when the LFS-HFS interval was increased to $40 \mathrm{~min}$, innocuous LFS did not attenuate L-LTP. Robust potentiation was observed with mean fEPSP slopes of $331 \pm 33 \%$ and $245 \pm 22 \%$, measured $5 \mathrm{~min}$ and $2 \mathrm{hr}$ after HFS, respectively. These were not statistically different from values of slices that received only HFS $(p>.1$, at all time points). In Figure $3 \mathrm{C}$ the data are presented so that fEPSP slopes measured at various times after induction of L-LTP can be compared. With the 20-min LFS-HFS interval, the decay of L-LTP back to pre-HFS baseline slope values (Fig. 3B, circles) was similar to the decay seen with the shorter 7-min LFS-HFS interval (Fig. 3A, circles). Levels of potentiation in slices receiving HFS alone, in slices receiving LFS $40 \mathrm{~min}$ before HFS, and in slices receiving LFS $5 \mathrm{~min}$ after the end of HFS were not statistically different from each other $(p>.1)$.

These results show that innocuous LFS $(5 \mathrm{~Hz}, 3 \mathrm{~min})$ maintains its inhibitory effect on L-LTP over a substantial period of time before induction of L-LTP. Innocuous LFS inhibited expression of L-LTP when HFS was applied up to 20 min after LFS. The inhibitory constraint of LFS on L-LTP had a limited duration, as L-LTP was intact when induced 40 min after LFS. This type of synaptic plasticity is a "silent" anterograde modification of L-LTP that is caused by prior

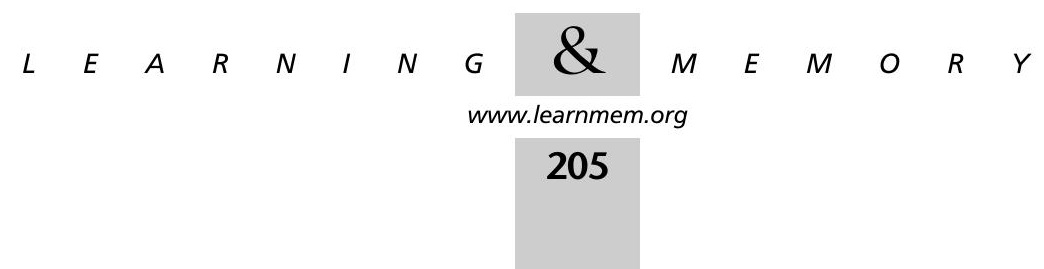


A

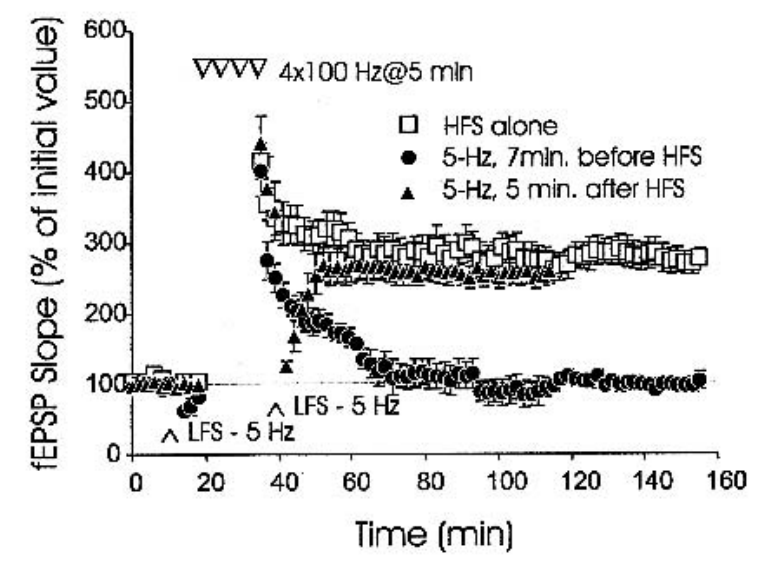

C

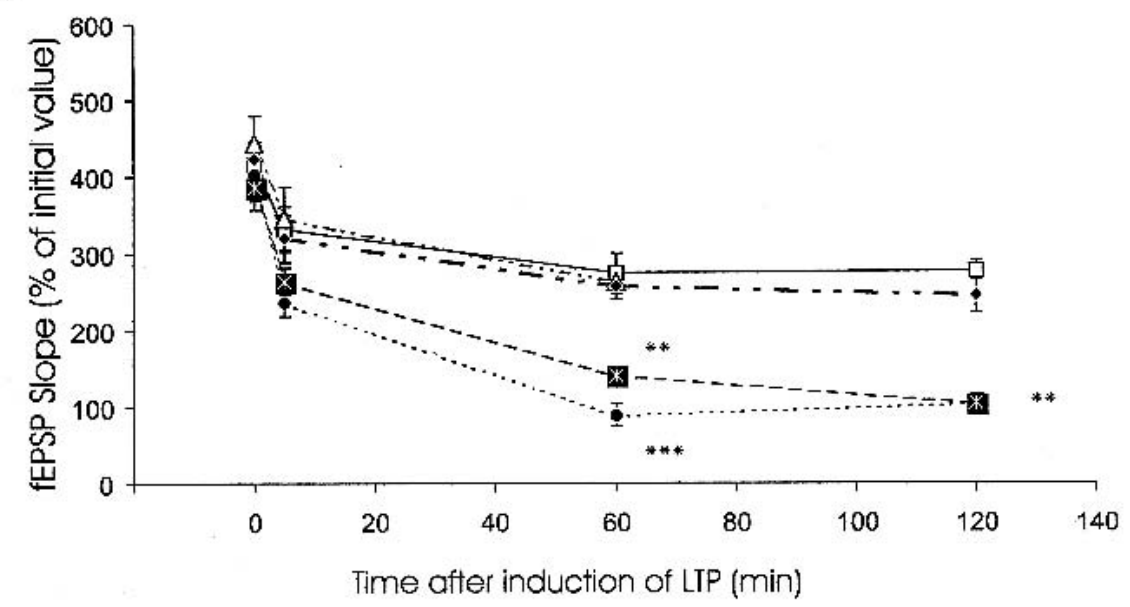

B

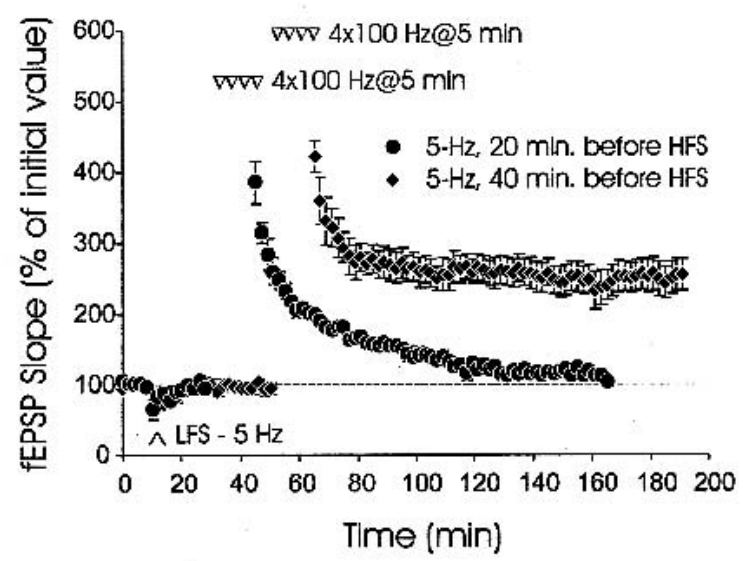

Figure 3 Innocuous LFS elicits anterograde metaplasticity of L-LTP only when given within a critical time window before L-LTP induction. (A) LFS induces anterograde, but not retrograde, suppression of L-LTP. When LFS (5 Hz, 3 min) was applied 7 min before tetraburst stimulation, L-LTP was blocked $(\bullet, n=4)$. However, when the same LFS was applied 5 min after tetraburst stimulation (triangles, $n=6$ ), transient DPT occurred, and the level of potentiation recovered to levels not significantly different from slices receiving tetraburst stimulation alone $(\square, n=6)$. ( $B)$ Increasing the time interval between LFS and L-LTP induction abolishes LFS-induced anterograde metaplasticity of L-LTP. Defective L-LTP was observed when LFS was applied 20 min before L-LTP induction $(\boldsymbol{\theta}, n=5)$. In contrast, normal L-LTP was seen when the time interval between LFS and tetraburst stimulation was extended to $40 \mathrm{~min}(\bullet, \mathrm{n}=6)$. (C) Summary plot showing levels of potentiation measured $5 \mathrm{~min}, 1 \mathrm{hr}, 2 \mathrm{hr}$, and immediately after tetraburst stimulation when the time between LFS and HFS was varied. (** denotes $p<.01$, *** denotes $p<.001$ ).

synaptic activity which, by itself, did not produce persistent changes in synaptic strength.

\section{Inhibition of L-LTP by Prior LFS Requires Activation of NMDA Receptors and Is Blocked by Inhibitors of PP1 and PP2A}

The LFS protocols that we have used to inhibit L-LTP resemble those known to induce hippocampal LTD and DPT (Barrionuevo et al. 1980; Staubli and Lynch 1990; Fujii et al. 1991; Dudek and Bear 1992). Both LTD and DPT require activation of protein phosphatases subsequent to NMDA receptor activation (Mulkey et al. 1993, 1994; O'Dell and Kandel 1994; for modeling data, see also Lisman 1989). To address whether L-LTP suppression by prior LFS requires NMDA receptor activation, we applied $25 \mu \mathrm{M}$ 2-amino-5phosphonopentanoic acid (APV), an NMDA receptor antagonist, to hippocampal slices before $5 \mathrm{~Hz}, 3 \mathrm{~min}$ LFS. After LFS, application of APV was stopped before subsequent HFS. In contrast to the decay of L-LTP observed when LFS was applied $20 \mathrm{~min}$ before induction (Fig. 3B, O), slices treated with APV during LFS (Fig. 4A, $\mathbf{\square}$ ) showed robust L-LTP that was not significantly different from L-LTP in slices receiving APV that was allowed to washout for a period of $20 \mathrm{~min}$ before receiving HFS (no LFS) (Fig. 4A, $\square ; p>.1$ at all time points). Mean fEPSP slopes for APV-treated LFS + HFS slices and APV-treated HFS slices were $252 \pm 32 \%$

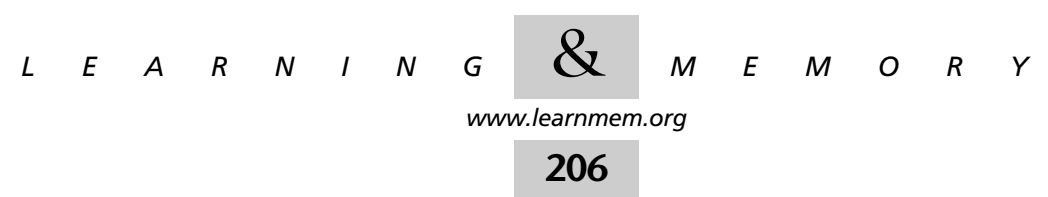


A

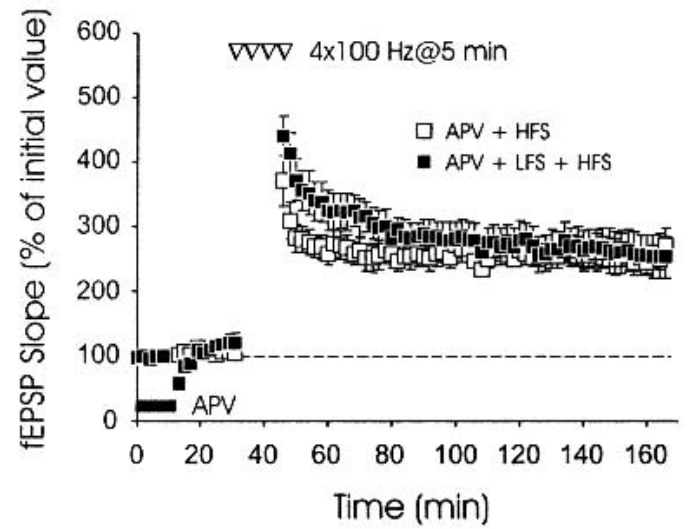

C $\quad \mathrm{OA}-5-\mathrm{Hz}, 20 \mathrm{~min}$. before HFS

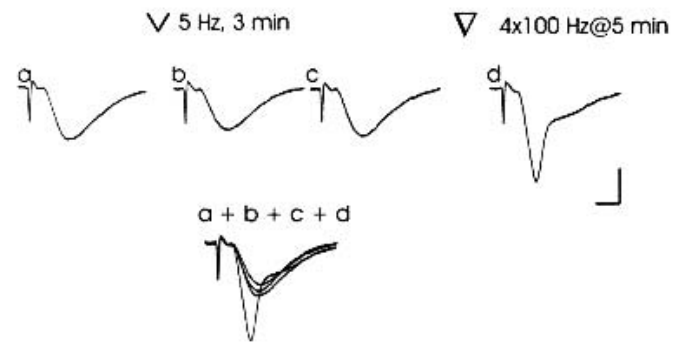

B
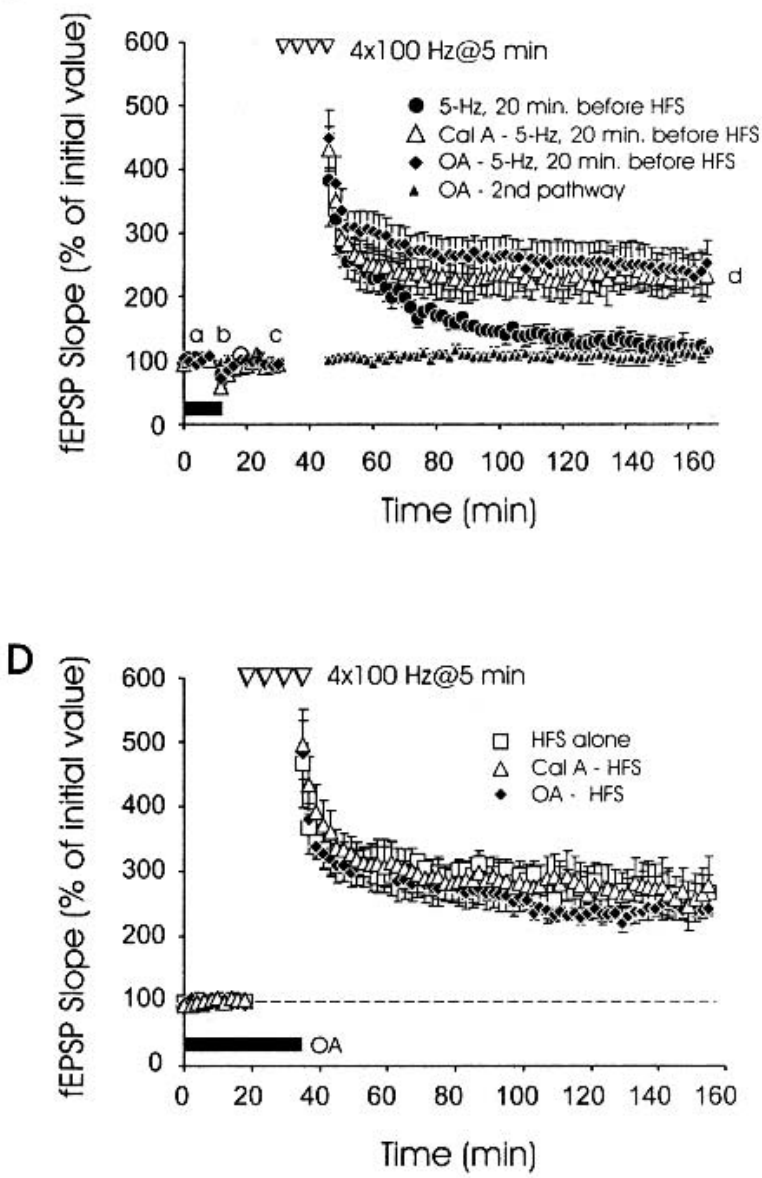

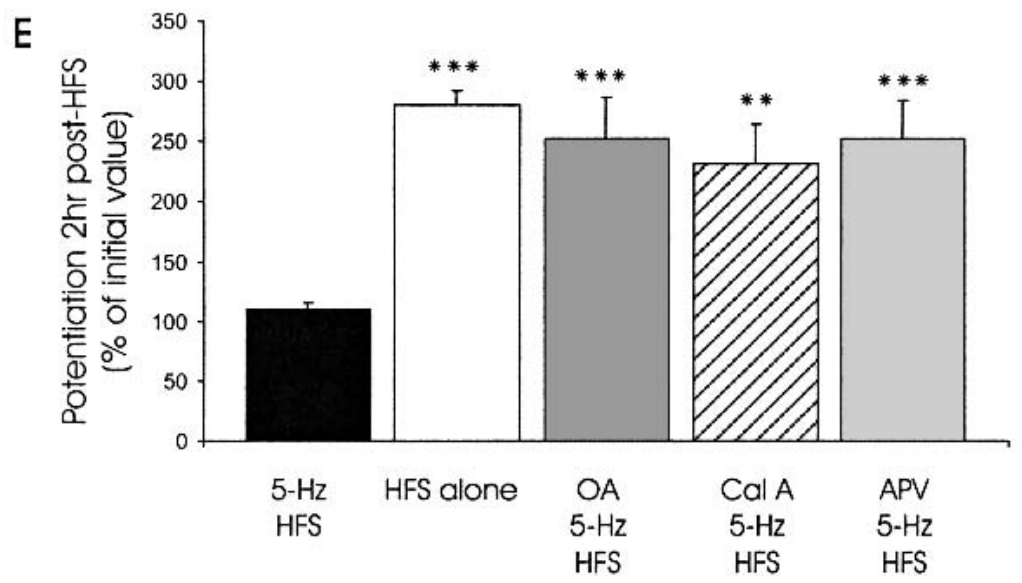

Figure 4 Inhibition of protein phosphatases or N-methyl-D-aspartate (NMDA) receptors blocks LFS-induced metaplasticity of L-LTP. (A) Application of 2-amino-5-phosphonopentanoic acid (APV), an NMDA receptor antagonist, blocks LFS-induced suppression of L-LTP. When APV was applied to slices and allowed to washout for $20 \mathrm{~min}$ (no LFS), robust L-LTP was elicited by HFS $(\square$, $n=4$ ). Similarly, when APV was applied to slices before and during LFS, robust L-LTP was induced by subsequent HFS $(\mathbf{\square}, n=5)$. (B) Robust L-LTP was observed in slices that received $5-\mathrm{Hz}$ LFS in the presence of okadaic acid $(\mathrm{OA})(1 \mu \mathrm{M}$, horizontal bar; $\bullet, \mathrm{n}=7)$ or calyculin $\mathrm{A}(\mathrm{Cal} A)($ open triangles, $\mathrm{n}=6)$. In contrast, slices receiving LFS without drug $(\bullet, n=5)$ showed deficient L-LTP. Application of OA did not alter basal synaptic transmission in a second independent pathway that did not receive either LFS or tetraburst stimulation (solid triangles, $n=7$ ). (C) Sample fEPSP traces from one experiment, showing OA blocking LFS-induced inhibition of L-LTP. Sample traces were recorded at times labeled on the graph (a-d). Note that fEPSPs have recovered to pre-LFS amplitudes and slope values before initiation of tetraburst stimulation. Calibration bars: $2 \mathrm{mV}$, 2 ms. (D) Protein phosphatase inhibitors do not affect L-LTP. LTP in slices pretreated with either OA $(\bullet, \mathrm{n}=5)$ or Cal A (triangles, $\mathrm{n}=5)$ was similar to LTP in drug-free slices receiving HFS $(\square, n=4)$. ( $E$ ) Summary bar graph depicting levels of potentiation seen 2 hr post-HFS in the presence of various inhibitors ( ${ }^{* *}$ denotes $p<.01,{ }^{* * *}$ denotes $p<.001$ compared with $5-\mathrm{Hz}$ HFS).

$$
\begin{array}{lllllllllllllll}
\text { L } & E & A & R & N & I & N & G & \mathcal{Z} & M & E & M & O & R & Y \\
\text { www.learnmem.org } & & &
\end{array}
$$


and $271 \pm 28 \%$ at $2 \mathrm{hr}$ postinduction, respectively $(p>.5)$. Thus, activation of NMDA receptors is required for LFS at 5 $\mathrm{Hz}$ to inhibit subsequent L-LTP (for E-LTP data, see Fujii et al. 1996).

Activation of PP1 and PP2A is critical for LFS-induced LTD and DPT (Mulkey et al. 1993, 1994; O'Dell and Kandel 1994; Huang et al. 2001; Morishita et al. 2001). PP1 and PP2A can also modulate the induction of LTP (Blitzer et al. 1995, 1998; see also Winder et al. 1998 and Allen et al. 2000). However, it is unclear whether PP1 and PP2A can modulate L-LTP by being activated well before its induction. Does anterograde inhibition of L-LTP by prior LFS require activation of PP1 and PP2A?

We observed that application of okadaic acid (OA), or preincubation of slices in calyculin A (Cal A), both inhibitors of PP1 and PP2A, blocked anterograde inhibition of L-LTP by prior LFS at $5 \mathrm{~Hz}, 3 \mathrm{~min}$ (Fig. 4B,C). Although transient synaptic depression was observed after LFS, L-LTP was still expressed after recovery from this depression in slices pretreated with OA or Cal A (Fig. 4B). Mean fEPSP slope at 2 -hr post-HFS was $113 \pm 10 \%$ in drug-free control slices receiving LFS $20 \mathrm{~min}$ before HFS (Fig. 4B, O). In contrast, the corresponding values in $\mathrm{OA}$ - and Cal A-treated slices (Fig. 4B, diamonds and open triangles) receiving prior LFS were $215 \pm 17 \%$ and $232 \pm 33 \%$, respectively, and they were significantly higher than control values $(p<.05)$. Preincubation of slices in Cal A, or application of OA just before and during tetraburst HFS, without prior LFS, did not affect L-LTP expression under the experimental conditions used here (Fig. $4 \mathrm{D}, p>.1$, at all time points). When a second independent pathway was monitored in some experiments, no effects of OA on fEPSPs elicited at $0.017 \mathrm{~Hz}$ (once per minute) were observed (Fig. 4B, solid triangles). These data show that LFS-induced anterograde inhibition of L-LTP requires activation of PP1 and PP2A (data summarized in Fig. 4E).

In summary, our data show that innocuous LFS at $5 \mathrm{~Hz}$ significantly inhibits the expression of the L-LTP without affecting E-LTP or persistently altering basal synaptic strength. This selective anterograde inhibition of L-LTP by prior innocuous synaptic activity is sensitive to the frequency, as well as the total amount, of stimulation. The inhibitory effect of innocuous LFS has a persistent duration that can last up to $20 \mathrm{~min}$ after LFS, but it is absent $40 \mathrm{~min}$ after LFS. Activation of PP1 and PP2A, and NMDA receptor activation, are required for anterograde inhibition of L-LTP by innocuous LFS.

\section{DISCUSSION}

Anterograde metaplasticity involves modulation, by electrical activity, of the capability for expression of future synaptic plasticity (Abraham and Bear 1996; Abraham and Tate 1997). Our present work has revealed a "silent" form of synaptic metaplasticity that involves specific modulation of
L-LTP by prior synaptic stimulation that is subthreshold for eliciting persistent changes in synaptic strength. The selectivity of the suppressive effects of prior innocuous LFS on L-LTP has a number of interesting implications. By inhibiting L-LTP, innocuous LFS may allow patterns of synaptic activity (e.g., multiple spaced trains) that would otherwise elicit persistent potentiation to produce shorter-lasting facilitation. This inhibition would prevent persistent saturation of postsynaptic responses during a time scale of 1-2 hr. The lack of effect on single-train E-LTP indicates that innocuous LFS may modulate mechanisms that are specifically needed for expression of L-LTP (see below). Thus, innocuous LFS before LTP induction may represent a "low-pass filter" that allows short-lasting facilitation (like single-train E-LTP) to occur while reducing future expression of L-LTP after repeated trains of synaptic stimuli.

\section{Metaplasticity of LTP by Stimulation Before LTP Induction}

LTP can be modulated by previous bouts of synaptic activity (Abraham and Bear 1996; Abraham and Tate 1997). For example, LFS at $1 \mathrm{~Hz}$ (1000 stimulation pulses), given before single-train LTP induction, substantially impaired E-LTP (Fujii et al. 1996). However, when LFS was increased to 5 $\mathrm{Hz}$ with the same number of stimulation pulses, no change in E-LTP was observed (Fujii et al. 1996; L-LTP was not examined in this study). Our finding that $5-\mathrm{Hz}$ LFS before tetraburst stimulation impaired L-LTP is consistent with the findings of Fujii et al. (1996) in that it supports a selective role for 5-Hz LFS in modulating L-LTP, but not E-LTP. Our data significantly extend previous work by showing that prior LFS exerts long-lasting, latent inhibition of subsequent L-LTP by engaging PP1 and PP2A.

Because stimulation-induced changes in basal synaptic efficacy can influence subsequent expression of LTP (Huang et al. 1992; Abraham and Huggett 1997), we used slices from adult mice that did not show LTD after 5-Hz LFS. We showed that this pattern of LFS did not persistently alter fEPSPs, but that it still inhibited subsequent L-LTP without affecting single-train E-LTP. By comparison, prior 5-Hz LFS of guinea-pig slices impairs E-LTP induction when given just $5 \mathrm{sec}$ before LTP induction (O'Dell and Kandel 1994). This inhibition of E-LTP induction may be dependent on protocol conditions (stimulation by O'Dell and Kandel was applied at a weaker intensity than that used here) and on animal species, but it too required phosphatase activity (O'Dell and Kandel 1994). It is important to note that HFS was given while fEPSPs were still depressed after LFS (O'Dell and Kandel 1994). Thus, the inhibition of E-LTP seen by O'Dell and Kandel may be explained by the fact that they induced E-LTP while antagonistic processes that lead to synaptic depression were already engaged. In contrast, we observed no inhibition of E-LTP in the present study, most likely because the considerable time lag between our

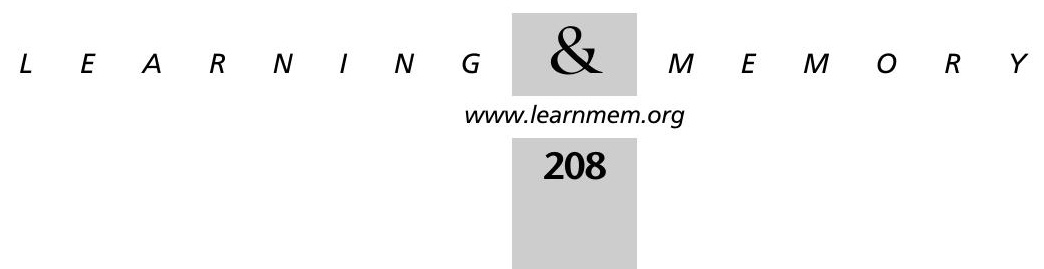


LFS and HFS was sufficient to allow depressive processes to subside before subsequent induction of E-LTP by a single train of $100-\mathrm{Hz}$ stimulation. In other studies, Abraham and Huggett (1997) and Huang et al. (1992) showed that repeated HFS that did not substantially alter synaptic strength blocked subsequent LTP induction. However, these studies did not test for selectivity of the effects of prior stimulation on E-LTP and L-LTP elicited by distinct amounts of stimulation. They also did not explore the roles of phosphatases in anterograde suppression of LTP by prior stimulation. Nonetheless, it is now evident that anterograde metaplastic regulation of LTP induction (O'Dell and Kandel 1994; Fujii et al. 1996; Abraham and Huggett 1997) and L-LTP expression (our present study) may be achieved by imposing various patterns of stimulation before LTP induction. Our present data reveal a previously unidentified, selective inhibition of L-LTP by innocuous patterns of LFS that requires PP1, PP2A, and NMDA receptor activation.

An intriguing finding in the present study is that L-LTP could not be reversed (depotentiated) by LFS applied after its induction by tetraburst stimulation. The mechanisms that modulate and gate reversibility of L-LTP by LFS applied after L-LTP induction ("retrograde DPT") are undefined. However, a plausible mechanism may involve protein synthesis and/or transcription, because these are required for robust expression of stable L-LTP, but they are not needed for E-LTP (Frey et al. 1988, 1996; Nguyen et al. 1994; Scharf et al. 2002). Indeed, genetic overexpression of a transcription factor, cyclic AMP-response element binding protein (CREB), in mouse hippocampal neurons can convert a decaying form of LTP into a stable type of LTP that is resistant to retrograde DPT (Barco et al. 2002).

\section{Protein Phosphatases and Synaptic Plasticity}

Protein kinases have long been regarded as key players in synaptic plasticity (for reviews, see Micheau and Riedel 1999 and Martin et al. 2000), but a plethora of studies have highlighted the importance of protein phosphatases in regulating bidirectional changes in synaptic strength (Mulkey et al. 1992, 1993, 1994; O'Dell and Kandel 1994; Blitzer et al. 1995, 1998; Wang and Kelly 1996, 1997; Winder et al. 1998; Yan et al. 1999; Allen et al. 2000; Winder and Sweatt 2001). In calcineurin knockout mice, bidirectional plasticity was modified with a change in the LTP/LTD threshold (Zeng et al. 2001). It has also been suggested that protein phosphatases may function as a "gate" that exerts a modifiable, PKAdependent inhibitory constraint on expression of LTP (Blitzer et al. 1995, 1998; Brown et al. 2000). Evidence that calcineurin acts as an inhibitory constraint on LTP is found in studies showing that genetic inhibition and enhancement of calcineurin facilitated and impaired LTP, respectively (Winder et al. 1998; Malleret et al. 2001). In support of the notion that phosphatases exert an inhibitory constraint on LTP, our data implicate PP1 and PP2A in blocking the ex- pression of L-LTP. Application of PP1 and PP2A inhibitors during LFS before L-LTP induction abolished anterograde inhibition of L-LTP. This finding supports the prediction that prior activation of PP1 and PP2A, in this case by LFS, should impair the expression of L-LTP (Blitzer et al. 1995).

Our results with Cal A differ from those reported by Thomas et al. (1996), in which they show that 5-Hz stimulation in Cal A potentiated transmission. In contrast, no such facilitation was reported here in this study, There are some potentially significant differences between their experimental conditions and ours, which might explain the apparent discrepancy in the data. Thomas et al. used a significantly higher concentration $(0.2 \%)$ of DMSO as solvent for Cal A; we have used $0.01 \%$ DMSO. It is possible that the combination of Cal A plus $0.2 \%$ DMSO might assist synaptic facilitation during $5-\mathrm{Hz}$ stimulation. Also, our slices were maintained at $28^{\circ} \mathrm{C}$, whereas the temperature used by Thomas et al. was $31^{\circ} \mathrm{C}$. We rejected all slices that produced maximal evoked fEPSP sizes smaller than $3 \mathrm{mV}$; it is unclear whether Thomas et al. did the same. If maximal fEPSPs were depressed in some slices, for whatever reason, then inhibition of phosphatases may enhance transmission in these slices during LFS at $5 \mathrm{~Hz}$. Finally, the flow rate of drug application was markedly higher in the study by Thomas et al. (1996). These factors might contribute to the facilitation seen during $5-\mathrm{Hz}$ stimulation by Thomas et al. These differences in experimental conditions do not refute the main findings and conclusions of these studies. Instead, the data underscore the notion that hippocampal synapses in area CA1 are exquisitely sensitive to a combination of relevant parameters under a given set of experimental conditions.

\section{How Might Phosphatases Mediate Anterograde Suppression of L-LTP by Prior LFS?}

Recently, Huang et al. (2001) showed that an LFS paradigm ( $2 \mathrm{~Hz}, 10 \mathrm{~min}$ ), similar to ours, significantly increased protein phosphatase activity in area CA1 of hippocampal slices. Also, LTD-inducing stimulation in vivo was associated with an increase in protein phosphatase activity (Thiels et al. 1998). Although we did not measure hippocampal levels of PP1 and PP2A activity, the blockade of anterograde suppression of L-LTP by two different inhibitors of PP1 and PP2A and the findings of these earlier studies indicate that LFS can engage phosphatases critical for anterograde suppression of L-LTP.

LFS-induced suppression of L-LTP may be caused by PP1 and PP2A acting on gene transcription. L-LTP requires transcription that is linked to the cAMP signaling pathway (Nguyen et al. 1994), and L-LTP may be caused by CREBmediated transcription. Phosphatases may move to the nucleus and dephosphorylate key transcription factors, such as CREB (Hagiwara et al. 1992; Bito et al. 1996). L-LTP may arise from augmented CREB-mediated transcriptional activity after reduced CREB dephosphorylation by PP1. This

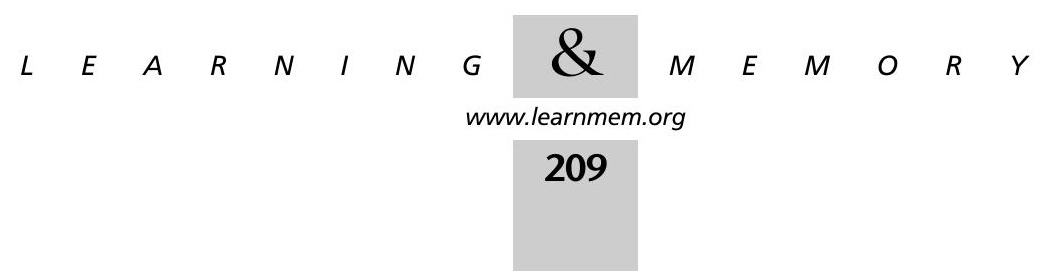


notion is consistent with previous work showing that CREmediated gene expression is stimulated by activity that induces L-LTP (Impey et al. 1996), and that CREB phosphorylation is enhanced after inhibition of phosphatases (Hagiwara et al. 1992; Bito et al. 1996). In our present study, LFS-induced engagement of PP1 and PP2A may have decreased CREB phosphorylation and reduced CRE-mediated transcription, thereby impairing L-LTP. Further work is needed to test whether the metaplastic suppression of LLTP reported here involves dephosphorylation of CREB.

Phosphatase-mediated anterograde suppression of L-LTP may involve extracellular signal-regulated kinase (ERK) and other mitogen-activated protein kinases (MAPKs). A link between phosphatases and ERK was shown when an LTD-inducing protocol decreased ERK immunoreactivity (Norman et al. 2000). This was simulated by incubation of hippocampal homogenates with purified PP1 and PP2A (Norman et al. 2000). Also, MEK inhibitors block the expression of L-LTP (English and Sweatt 1997; for reviews, see Impey et al. 1999 and Sweatt 2001) and inhibit activitydependent gene transcription (Impey et al. 1998). The MAPK cascade is activated by synaptic stimulation (English and Sweatt 1996) and by increases in cAMP, implicating cross-talk between the PKA and ERK/MAPK pathways (Impey et al. 1998). Thus, activation of phosphatases by innocuous LFS might inhibit subsequent L-LTP by suppressing activation of the MAPK and PKA pathways. However, this notion is difficult to test in the context of LFS-induced metaplasticity, because slice application of MAPK and PKA inhibitors or activators per se interferes with L-LTP (Frey et al. 1993; Huang and Kandel 1994; English and Sweatt 1997; Impey et al. 1999).

Additional mechanisms by which LFS modulates L-LTP may involve dephosphorylation of glutamate receptors and reduction of PKC activity. LTD induction in hippocampal slices (Hrabetova and Sacktor 1996) and in vivo (Thiels et al. 2000) is correlated with decreased PKC activity that can be blocked by pharmacological inhibition of protein phosphatase activity (Thiels et al. 2000). LFS-induced LTD is also associated with dephosphorylation of AMPA receptors (Barria et al. 1997; Lee et al. 2000). Because PKC and AMPA receptors are needed for LTP (Abeliovich et al. 1993; Zamanillo et al. 1999), we speculate that protein phosphatases may modulate L-LTP by acting on these molecular targets after LFS.

\section{Behavioral Implications}

The demonstration that L-LTP may be linked to specific types of long-term memory in mice (Abel et al. 1997) prompts us to hypothesize that anterograde metaplasticity of L-LTP in the hippocampus might translate into altered expression of some types of hippocampus-dependent longterm, but not short-term, memory. Recent experience can modify memory processing and consolidation, and it may gate the flow of information into long-term memory storage via the engagement of signaling molecules such as protein phosphatases. It is interesting that specific types of behavioral experiences, such as chronic drug abuse and addiction, can distort long-term memory (for review, see Schacter 1995). For example, suppression of traumatic memories in humans may involve neuromodulatory actions of endogenous substances, such as release of opiates during a painful experience (Gallagher et al. 1985). However, linking certain behavioral experiences to synaptic activity and metaplasticity of L-LTP in brain structures important for long-term memory remains a stimulating challenge.

\section{MATERIALS AND METHODS}

\section{Animals}

Female C57BL/6 mice, aged 9-12 wk (Charles River) were used for all experiments. At these ages, hippocampal slices did not show LTD when LFS at $1 \mathrm{~Hz}, 15 \mathrm{~min}$ was applied to the Schaffer collateral pathway in area CA1 (data not shown). Animals were housed at the University of Alberta using guidelines approved by the Canadian Council on Animal Care.

\section{Electrophysiology}

Transverse hippocampal slices (400- $\mu \mathrm{m}$ thickness) were prepared as described by Nguyen and Kandel (1997). Slices were maintained in an interface chamber at $28^{\circ} \mathrm{C}$ and were perfused $(1 \mathrm{~mL} / \mathrm{min})$ with artificial cerebrospinal fluid (ACSF; composition as described in Nguyen and Kandel 1997) aerated with $95 \% \mathrm{O}_{2}$ and $5 \% \mathrm{CO}_{2}$. Extracellular fEPSPs were recorded with a glass microelectrode (2-3 M $\Omega$, filled with ACSF) positioned in stratum radiatum of area CA1. A bipolar nickel-chromium stimulating electrode was used to elicit fEPSPs by stimulation of the Schaffer collateral fibers. Stimulation intensity ( $0.08 \mathrm{~ms}$ pulse duration) was adjusted to evoke fEPSP amplitudes that were $\sim 40 \%$ of maximum size. Evoked fEPSPs were elicited once per minute at this test stimulation intensity. Slices that showed maximal fEPSPs $<3 \mathrm{mV}$ were rejected.

LTP was induced by applying either a single $1-\mathrm{sec}$ train (100 $\mathrm{Hz}$, at test strength) to induce E-LTP (Huang and Kandel 1994), or four 1-sec trains $(100 \mathrm{~Hz}$, test strength) spaced 5 min apart to elicit L-LTP (Abel et al. 1997; Nguyen et al. 2000). The latter "tetraburst" protocol induces protein synthesis-dependent L-LTP in CA1 of mouse slices (Scharf et al. 2002). LFS was applied by giving one of the following protocols: $5 \mathrm{~Hz}$ for $3 \mathrm{~min}, 5 \mathrm{~Hz}$ for $30 \mathrm{sec}, 1 \mathrm{~Hz}$ for $15 \mathrm{~min}$, or $1 \mathrm{~Hz}$ for $3 \mathrm{~min}$ before LTP induction. For some experiments, a second independent pathway was monitored to gauge the effects of applied drugs on basal synaptic strength. This "control" pathway received only stimulation at the rate of once per minute (Nguyen et al. 1994).

An NMDA receptor antagonist, 2-amino-5-phosphonopentanoic acid (APV; Research Biochemicals International), was prepared as a concentrated stock solution in distilled water, and it was bath-applied (after dilution to $25 \mu \mathrm{M}$ in ACSF) to slices in some experiments. The PP1 and PP2A inhibitors, sodium OA (SigmaAldrich) and Cal A (Biomol), were prepared as concentrated stock solutions in distilled water and in DMSO, respectively. Each drug was diluted in ACSF to the desired concentration. The final concentration of DMSO did not exceed $0.01 \%$; at this concentration, DMSO did not affect basal synaptic transmission or LTP (data not

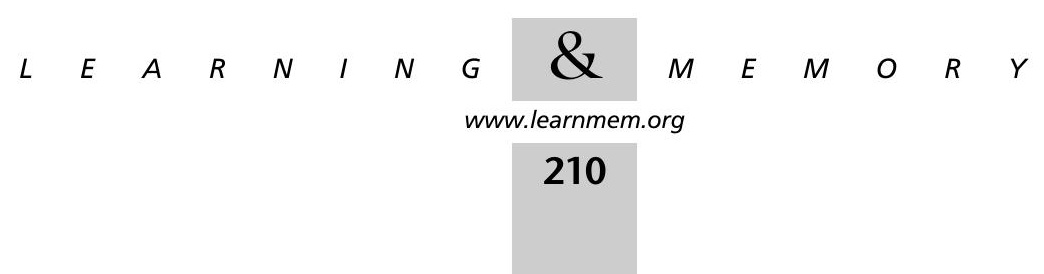


shown). Sodium OA was bath-applied for $20 \mathrm{~min}$ before the start of baseline acquisition and it was washed out starting immediately after LFS (Fig. 4B) or, in some experiments, after HFS (Fig. 4D) . All experiments using sodium OA were performed under dimmed-light conditions. For Cal A experiments, slices were incubated in drug for $40 \mathrm{~min}$ before start of baseline recordings, and Cal A was washed out just after LFS (Fig. $4 \mathrm{~B}$ ) or, in some experiments, after HFS (Fig. 4D). Drug experiments were interleaved with drug-free controls.

\section{Data Analysis}

The initial slope of the fEPSP was measured as an index of synaptic strength (Johnston and Wu 1995). Average "baseline" slope values were measured during a period of $20 \mathrm{~min}$ before $100-\mathrm{Hz}$ stimulation. Student's $t$ test (two groups) or an analysis of variance (ANOVA) with a Tukey-Kramer post-test (three or more groups) was used for statistical comparisons of mean fEPSP slopes, with a significance level of $p<.05$. All values shown are mean \pm standard error of mean (SEM), with $\mathrm{n}=$ number of slices.

\section{ACKNOWLEDGMENTS}

We thank Mark Bear, Vincent Castellucci, and Tom O'Dell for their constructive comments on an earlier version of this manuscript. This work was supported by grants from the Canadian Institutes of Health Research (formerly the MRC of Canada), the Alberta Heritage Foundation for Medical Research (AHFMR), the Canadian Neurotrauma Research Program (Alberta Paraplegic Association), and the Natural Sciences and Engineering Research Council of Canada (NSERC). N. H. Woo holds an NSERC Postgraduate Scholarship and an AHFMR Studentship. P. Nguyen is a Scholar of the AHFMR and MRC.

The publication costs of this article were defrayed in part by payment of page charges. This article must therefore be hereby marked "advertisement" in accordance with 18 USC section 1734 solely to indicate this fact.

\section{REFERENCES}

Abel, T., Nguyen, P.V., Barad, M., Deuel, T., Kandel, E.R., and Bourtchouladze, R. 1997. Genetic demonstration of a role for PKA in the late phase of LTP and in hippocampus-based long-term memory. Cell 88: 615-626.

Abeliovich, A., Chen, C., Goda, Y., Silva, A.J., Stevens, C.F., and Tonegawa, S. 1993. Modified hippocampal long-term potentiation in PKC-gamma mutant mice. Cell 75: 1253-1262.

Abraham, W. and Bear, M.F. 1996. Metaplasticity: The plasticity of synaptic plasticity. Trends Neurosci. 19: 126-130.

Abraham, W.C. and Huggett, A. 1997. Induction and reversal of LTP by repeated high-frequency stimulation in rat hippocampal slices. Hippocampus 7: 137-145.

Abraham, W.C. and Tate, W.P. 1997. Metaplasticity: A new vista across the field of synaptic plasticity. Prog. Neurobiol. 52: 303-323.

Alger, B.E. and Teyler, T.J. 1976. Long-term and short-term plasticity in the CA1, CA3, and dentate regions of the rat hippocampal slice. Brain Res. 110: 463-482.

Allen, P.B., Hvalby, O., Jensen, V., Errington, M.L., Ramsay, M., Chaudry, F., Bliss, T.V.P., Storm-Mathisen, J., Morris, R.G.M., Andersen, P., et al. 2000. Protein phosphatase-1 regulation in the induction of LTP: Heterogeneous molecular mechanisms. J. Neurosci. 20: 3527-3543.

Andersen, P., Sundberg, S.H., Sveen, O., and Wigström, H. 1977. Specific long-lasting potentiation of synaptic transmission in hippocampal slices. Nature 266: 736-737.
Barco, A., Alarcon, J.M., and Kandel, E.R. 2002. Expression of a constitutively active CREB protein facilitates the late phase of LTP by enhancing synaptic capture. Cell 108: 689-703.

Barria, A., Muller, D., Derkach, V., Griffith, L.C., and Soderling, T.R. 1997 Regulatory phosphorylation of AMPA-type glutamate receptors by CaM-KII during LTP. Science 276: 2042-2045.

Barrionuevo, G., Schottler, F., and Lynch, G. 1980. The effects of repetitive low-frequency stimulation on control and "potentiated" synaptic responses in the hippocampus. Life Sci. 27: 2385-2391.

Bito, H., Deisseroth K., and Tsien, R.W. 1996. CREB phosphorylation and dephosphorylation: $\mathrm{A} \mathrm{Ca}^{2+}$ - and stimulus duration-dependent switch for hippocampal gene expression. Cell 87: 1203-1214.

Bliss, T.V.P. and Collingridge, G.L. 1993. A synaptic model of memory: Long-term potentiation in the hippocampus. Nature 361: 31-39.

Bliss, T.V.P. and Lomo, T. 1973. Long-lasting potentiation of synaptic transmission in the dentate area of the anaesthetized rabbit following stimulation of the perforant path. J. Physiol. 232: 331-356.

Blitzer, R.D., Wong, T., Nouranifar, R., Iyengar, R., and Landau, E.M. 1995. Postsynaptic cAMP pathway gates early LTP in hippocampal CA1 region. Neuron 15: 1403-1414.

Blitzer, R.D., Connor, J.H., Brown, G.P., Wong, T., Shenolikar, S., Iyengar, R., and Landau, E.M. 1998. Gating of CaMKII by cAMP-regulated protein phosphatase activity during LTP. Science 280: 1940-1942.

Brown, G.P., Blitzer, R.D., Connor, J.H., Wong, T., Shenolikar, S., Iyengar, R., and Landau, E.M. 2000. LTP induced by theta frequency stimulation is regulated by a protein phosphatase-1-operated gate. J. Neurosci. 20: $7880-7887$.

Brun, V.H., Ytterbo, K., Morris, R.G.M., Moser, M.B., and Moser, E.I. 2001. Retrograde amnesia for spatial memory induced by NMDA receptor-mediated LTP. J. Neurosci. 21: 356-362.

Chen, Y.L., Huang, C.C., and Hsu, K.S. 2001. Time-dependent reversal of long-term potentiation by low-frequency stimulation at the hippocampal mossy fiber-CA3 synapses. J. Neurosci. 21: 3705-3714.

Christie, B.R. and Abraham, W.C. 1992. Priming of associative long-term depression by theta frequency synaptic activity. Neuron 8: 79-84.

Dudek, S.M. and Bear, M.F. 1992. Homosynaptic LTD in area CA1 of hippocampus and effects of NMDA receptor blockade. Proc. Natl. Acad. Sci. 89: 4363-4367.

- 1993. Bidirectional long-term modification of synaptic effectiveness in the adult and immature hippocampus. J. Neurosci. 13: 2910-2918.

English, J.D. and Sweatt, J.D. 1996. Activation of p42 mitogen-activated protein kinase in hippocampal LTP. J. Biol. Chem. 271: 24329-24332

1997. A requirement for the mitogen-activated protein kinase cascade in hippocampal long term potentiation. J. Biol. Chem. 272: 19103-19106.

Frey, U., Krug, M., Reymann, K.G., and Matthies, H. 1988. Anisomycin, an inhibitor of protein synthesis, blocks the late phase of LTP phenomena in the hippocampal CA1 region in vitro. Brain Res. 45: 57-65.

Frey, U., Huang, Y-Y, and Kandel, E.R. 1993. Effect of cAMP simulate a late stage of LTP in hippocampal CA1 neurons. Science 260: 1661-1664

Frey, U., Frey, S., Schollmeier, F., and Krug, M. 1996. Influence of actinomycin D, a RNA synthesis inhibitor, on long-term potentiation in rat hippocampal neurons in vivo and in vitro. J. Physiol. 490: 703-711.

Fujii, S., Saito, K., Miyakawa, H., Ito, K., and Kato, H. 1991. Reversal of long-term potentiation (depotentiation) induced by tetanus stimulation of the input to CA1 neurons of guinea pig hippocampal slices. Brain Res. 555: 112-122.

Fujii, S., Kuroda, Y., Miura, M., Furuse, H., Sasaki, H., Kaneko, K., Ito, K., Chen, Z., and Kato, H. 1996. The long-term suppressive effect of prior activation of synaptic inputs by low-frequency stimulation on induction of long-term potentiation in CA1 neurons of guinea pig hippocampal slices. Exp. Brain Res. 111: 305-312.

Gallagher, M., Rapp, P., and Fanelli, R.J. 1985. Opiate antagonist

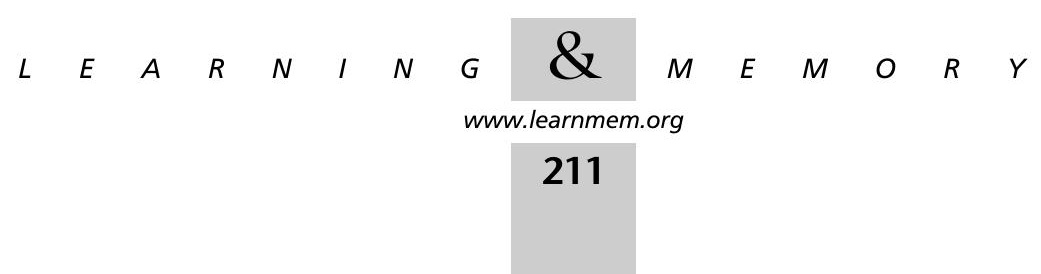


facilitation of time-dependent memory processes: Dependence on intact norepinephrine function. Brain Res. 347: 284-290.

Hagiwara, M., Alberts, A., Brindle, P., Meinkoth, J., Feramisco, J., Deng, T., Karin, M., Shenolikar, S., and Montminy, M. 1992. Transcriptional attenuation following cAMP induction requires PP-1-mediated dephosphorylation of CREB. Cell 70: 105-113.

Hrabetova, S. and Sacktor, T.C. 1996. Bidirectional regulation of protein kinase-M in the maintenance of LTP and LTD. J. Neurosci. 16: 5324-5333.

Huang, Y.Y. and Kandel, E.R. 1994. Recruitment of long-lasting and protein kinase A-dependent long-term potentiation in the CA1 region of hippocampus requires repeated tetanization. Learn. Mem. 1: 74-82.

Huang, Y.Y., Colino, A., Selig, D.K., and Malenka, R.C. 1992. The influence of prior synaptic activity on the induction of long-term potentiation. Science 255: 730-733

Huang, Y.Y., Nguyen, P.V., Abel, T., and Kandel, E.R. 1996. Long-lasting forms of synaptic potentiation in the mammalian hippocampus. Learn. Mem. 3: 74-85.

Huang, C.C., Liang, Y.C., and Hsu, K.S. 2001. Characterization of the mechanism underlying the reversal of long term potentiation by low frequency stimulation at hippocampal CA1 synapses. J. Biol. Chem. 276: $48108-48117$.

Impey, S., Mark, M., Villacres, E.C., Poser, S., Chavkin, C., and Storm, D.R 1996. Induction of CRE-mediated gene expression by stimuli that generate long-lasting LTP in area CA1 of the hippocampus. Neuron 16: $973-982$.

Impey, S., Obrietan, K., Wong, S.T., Poser, S., Yano, S., Wayman, G., Deloulme, J.C., Chan, G., and Storm, D.R. 1998. Cross talk between ERK and PKA is required for $\mathrm{Ca}^{2+}$ stimulation of CREB-dependent transcription and ERK nuclear translocation. Neuron 21: 869-883.

Impey, S., Obrietan, K., and Storm, D.R. 1999. Making new connections: Role of ERK/MAP kinase signaling in neuronal plasticity. Neuron 23 11-14.

Johnston, D. and Wu, S.M.-S. 1995. Foundations of cellular neurophysiology. In Extracellular field recordings, pp. 423-429. MIT Press, Cambridge, MA

Kandel, E.R. 2001. The molecular biology of memory storage: A dialogue between genes and synapses. Science 294: 1030-1038.

Krug, M., Loessner, B., and Ott, T. 1984. Anisomycin blocks the late phase of LTP in the dentate gyrus of freely moving rats. Brain Res. Bull. 13: 39-42.

Lee, H.K., Barbarosie, M., Kameyama, K., Bear, M.F., and Huganir, R.L. 2000. Regulation of distinct AMPA receptor phosphorylation sites during bidirectional synaptic plasticity. Nature 405: 955-959.

Lisman, J. 1989. A mechanism for the Hebb and the anti-Hebb processes underlying learning and memory. Proc. Natl. Acad. Sci. 86: 9574-9578.

Malleret, G., Haditsch, U., Genoux, D., Jones, M.W., Bliss, T.V.P., Vanhoose, A.M., Weilauf, C., and Kandel, E.R. 2001. Inducible and reversible enhancement of learning, memory and long-term potentiation by genetic inhibition of calcineurin. Cell 104: 675-686.

Martin, S., Grimwood, P., and Morris, R.G.M. 2000. Synaptic plasticity and memory: An evaluation of the hypothesis. Annu. Rev. Neurosci. 23: 649-711.

Matthies, H. and Reymann, K.G. 1993. Protein kinase A inhibitors prevent the maintenance of hippocampal LTP. Neuroreport 4: 712-714

Mayford, M., Wang, J., Kandel, E.R., and O'Dell, T. 1995. CaMKII regulates the associativity function of hippocampal synapses for the production of both LTD and LTP. Cell 81: 891-904.

Micheau, J. and Riedel, G. 1999. Protein kinases: Which one is the memory molecule? Cell. Mol. Life Sci. 55: 534-548.

Montgomery, J.M. and Madison, D.V. 2002. State-dependent heterogeneity in synaptic depression between pyramidal cell pairs. Neuron 33: $765-777$

Morishita W., Connor, J.H., Xia, H., Quinlan, E.M., Shenolikar, S., and Malenka, R.C. 2001. Regulation of synaptic strength by protein phosphatase-1. Neuron 32: 1133-1148.
Moser, E.I., Krobert, K.A., Moser, M.B., and Morris, R.G.M. 1998. Impaired spatial learning after saturation of long-term potentiation. Science 281: 2038-2042.

Mulkey, R.M. and Malenka, R.C. 1992. Mechanisms underlying induction of homosynaptic long-term depression in area CA1 of the hippocampus. Neuron 9: 967-975.

Mulkey, R.M., Herron, C.E., and Malenka, R.C. 1993. An essential role for protein phosphatases in hippocampal long-term depression. Science 261: 1051-1055.

Mulkey, R.M., Endo, S., Shenolikar, S., and Malenka, R.C. 1994. Involvement of a calcineurin/inhibitor-1 phosphatase cascade in hippocampal long-term depression. Nature 369: 486-488.

Nguyen, P.V. and Kandel, E.R. 1997. Brief theta-burst stimulation induces a transcription-dependent late phase of LTP requiring cAMP in area CA1 of the mouse hippocampus. Learn. Mem. 4: 230-243.

Nguyen, P.V., Abel, T., and Kandel, E.R. 1994. Requirement of a critical period of transcription for induction of late phase of LTP. Science 265: 1104-1107.

Nguyen, P.V., Duffy, S.N., and Young, J.Z. 2000. Differential maintenance and frequency-dependent tuning of LTP at hippocampal synapses of specific strains of inbred mice. J. Neurophysiol. 84: 2484-2493.

Norman, E.D., Thiels, E., Barrionuevo, G., and Klann, E. 2000. Long-term depression in the hippocampus in vivo is associated with protein phosphatase-dependent alterations in extracellular signal-regulated kinase. J. Neurochem. 74: 192-198.

O'Dell, T.J. and Kandel, E.R. 1994. Low-frequency stimulation erases LTP through an NMDA receptor-mediated activation of protein phosphatases. Learn. Mem. 1: 129-139.

Scharf, M., Woo, N., Lattal, K.M., Young, J.Z., Nguyen, P.V., and Abel, T. 2002. Protein synthesis is required for the enhancement of LTP and long-term memory by spaced training. J. Neurophysiol. 87: 2770-2777.

Schwartzkroin, P. and Wester, K. 1975. Long-lasting facilitation of synaptic potential following tetanization in the in vitro hippocampal slice. Brain Res. 89: 107-119.

Stanton, P.K. and Sarvey, J.M. 1984. Blockade of long-term potentiation in rat hippocampal slices by inhibitors of protein synthesis. J. Neurosci. 4: 3080-3088.

Staubli, U. and Lynch, G. 1990. Stable depression of potentiated synaptic responses in hippocampus with $1-5 \mathrm{~Hz}$ stimulation. Brain Res. 513: 113-118.

Swain, R.A., Armstrong, K.E., Comery, T.A., Humphreys, A.G., Jones, T.A Klein, J.A., and Greenough, W.T. 1995. Speculations on the fidelity of memories stored in synaptic connections. In Memory distortion. How minds, brains, and societies reconstruct the past (ed. D.L. Schacter), pp. 274-297. Harvard University Press, Cambridge, MA.

Sweatt, J.D. 2001. The neuronal MAP kinase cascade: A biochemical signal integration system subserving synaptic plasticity and memory. $J$. Neurochem. 76: 1-10.

Thiels, E., Norman, E.D., Barrionuevo, G., and Klann, E. 1998. Transient and persistent increases in protein phosphatase activity during long-term depression in the adult hippocampus in vivo. Neuroscience 86: $1023-1029$.

Thiels, E., Kanterewicz, B.I., Knapp, L.T., Barrionuevo, G., and Klann, E. 2000. Protein phosphatase-mediated regulation of protein kinase $C$ during LTD in the adult hippocampus in vivo. J. Neurosci. 20: 7199-7207.

Thomas, M.J., Moody, T.D., Makhinson, M., and O'Dell, T.J. 1996 Activity-dependent b-adrenergic modulation of low frequency stimulation induced LTP in the hippocampal CA1 region. Neuron 17: 475-482.

Thomas, M.J., Watanabe, A.M., Moody, T.D., Makhinson, M., and O'Dell, T.J. 1998. Postsynaptic complex spike bursting enables the induction of LTP by theta frequency synaptic stimulation. J. Neurosci. 18: 7118-7126.

Wagner, J.J. and Alger, B.E. 1995. GABAergic and developmental influences on homosynaptic LTD and depotentiation in rat hippocampus. J. Neurosci. 15: 1577-1586.

Wang, J.H. and Kelly, P.T. 1996. The balance between postsynaptic

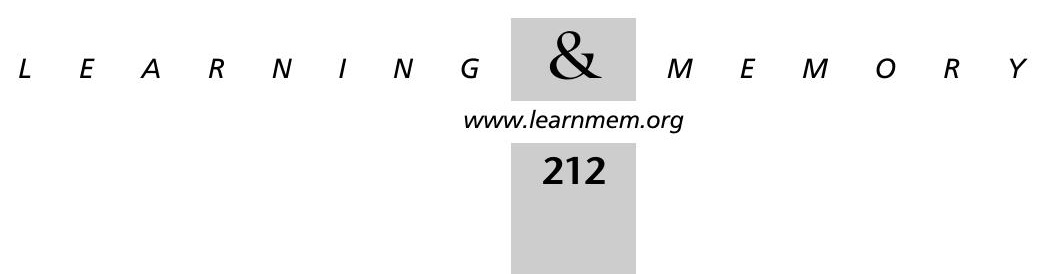


$\mathrm{Ca}^{2+}$-dependent protein kinase and phosphatase activities controlling synaptic strength. Learn. Mem. 3: 170-181.

. 1997. Postsynaptic calcineurin activity downregulates synaptic transmission by weakening intracellular $\mathrm{Ca}^{2+}$ signaling mechanisms in hippocampal CA1 neurons. J. Neurosci. 17: 4600-4611.

Wexler, E.M. and Stanton, P.K. 1993. Priming of homosynaptic long-term depression in hippocampus by previous synaptic activity. Neuroreport 4: 591-594.

Winder, D.G. and Sweatt, J.D. 2001. Roles of serine/threonine phosphatases in hippocampal synaptic plasticity. Nat. Rev. Neurosci. 2: 461-474.

Winder, D.G., Mansuy, I.M., Osman, M., Moallem, T.M., and Kandel, E.R. 1998. Genetic and pharmacological evidence for a novel, intermediate phase of long-term potentiation suppressed by calcineurin. Cell 92: $25-37$.

Winder, D.G., Martin, K.C., Muzzio, I.A., Rohrer, D., Chrucinski, A., Kobilka, B., and Kandel, E.R. 1999. ERK plays a regulatory role in induction of LTP by theta frequency stimulation and its modulation by b-adrenergic receptors. Neuron 24: 715-726.

Woo, N.H., Duffy, S.N., Abel, T., and Nguyen, P.V. 2000. Genetic and pharmacological demonstration of differential recruitment of
cAMP-dependent protein kinases by synaptic activity. J. Neurophysiol. 84: 2739-2745.

Yan, Z., Hsieh-Wilson, L., Feng, J., Tomizawa, K., Allen, P.B., Fienberg, A.A., Nairn, A.C., and Greengard, P. 1999. Protein phosphatase-1 modulation of neostriatal AMPA channels: Regulation by DARPP-32 and spinophilin. Nat. Neurosci. 2: 13-17.

Yang, X.D. and Faber, D.S. 1991. Initial synaptic efficacy influences induction and expression of long-term changes in transmission. Proc. Natl. Acad. Sci. 88: 4299-4304.

Zamanillo, D., Sprengel, R., Hvalby, O., Jensen, V., Burnashev, N., Rozov, A., Kaiser, K., Koster, H., Borchardt, T., Worley, P., et al. 1999. Importance of AMPA receptors for hippocampal synaptic plasticity but not for spatial learning. Science 284: 1805-1811.

Zeng, H., Chattarji, S., Barbarosie, M., Rondi-Reig, L., Philpot, B.D., Miyakawa, T., Bear, M.F., and Tonegawa, S. 2001. Forebrain-specific calcineurin knockout selectively impairs bidirectional synaptic plasticity and working/episodic-like memory. Cell 107: 617-629.

Received April 22, 2002; accepted in revised form June 7, 2002. 


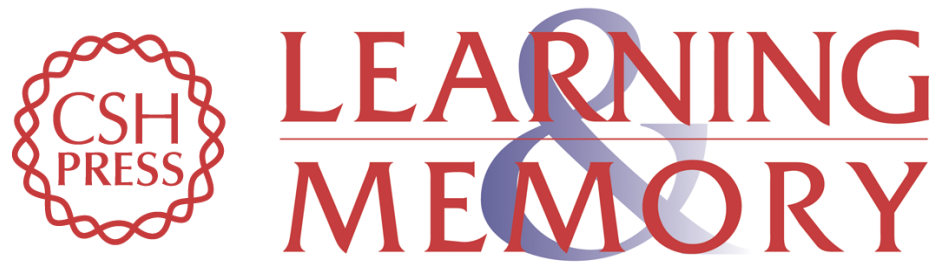

\section{"Silent" Metaplasticity of the Late Phase of Long-Term Potentiation Requires Protein Phosphatases}

Newton H. Woo and Peter V. Nguyen

Learn. Mem. 2002, 9:

Access the most recent version at doi:10.1101//m.498402

References This article cites 77 articles, 30 of which can be accessed free at:

http://learnmem.cshlp.org/content/9/4/202.full.html\#ref-list-1

License

Email Alerting Receive free email alerts when new articles cite this article - sign up in the box at the Service top right corner of the article or click here. 